ISSN: 2162-3104 Print/ ISSN: 2166-3750 Online

Volume 6, Issue 1 (2016), pp. 175-194

(C) Journal of International Students

http://jistudents.org/

\title{
International Students in Transition: Voices of Chinese Doctoral Students in a U.S. Research University
}

\author{
Yi (Leaf) Zhang \\ University of Texas at Arlington (USA)
}

\begin{abstract}
In this study, I focused on international Chinese doctoral students and sought to better understand their lived experience in transition to U.S. higher education. I also aimed to explore strategies that can be employed to improve these students' academic and sociocultural experiences on American campuses. Guided by the adult transition theory (Goodman, Schlossberg \& Anderson, 2006), this study used an interpretive phenomenological method. Qualitative data were collected from in-depth focus group interviews. The findings of this study informed higher education educators and practitioners about unique challenges faced by international Chinese graduates in transition and provided insightful knowledge for new practice, programs, and policies that can be created to improve international students' transition and success.
\end{abstract}

\section{Keywords}

International student, adult transition, Chinese doctoral students, U.S. higher education, qualitative

International students make up a significant proportion of students in U.S. higher education and have received increasing attention in the past decades. The increase in international student enrollment has changed the demographics of student populations on many American campuses and challenged U.S. educators to rethink student learning and teaching in higher education (Huang, 2012). Mainland China remained as the top sending country of international students for the third year in row. In 2012/13 
academic year, 235,597 Chinese students enrolled in U.S. higher education, which constituted more than one fourth of the total international student population in the U.S. (Institute of International Education, 2013a). The majority of these Chinese students (43.9\%) study at a graduate level (Institute of International Education, 2013b) and represent a significant percentage of international students obtaining doctoral degrees each year. Approximately $40 \%$ of all doctoral degrees granted in 2011 to international students went to citizens from mainland China (National Science Foundation, 2012).

International students, particularly those who enrolled in doctoral programs, are important contributors in many fields of study, such as medicine, science, engineering, mathematics, and technology (Brainard, 2005; Le \& Gardner, 2010; Feller, 2005). They not only contribute to research activities in these fields, but also serve as teaching assistants for various undergraduate courses and laboratory sections (Peterson, Briggs, Dreasher, Horner, \& Nelson, 1999). As with other international student groups, international doctoral students provide opportunities for American students to explore different cultures, to be exposed to multiple points of view, and to gain a better understanding about diversity (Dalton, 1999; Heyward, 2002). International students are also significant contributors to the U.S. economy. During the 2011/12 academic year, international students and their dependents contributed more than \$21 billion dollars to U.S. economy (NAFSA, 2012).

Despite the significant contribution of international students to the U.S. and the large proportion of international Chinese doctoral students, it is relatively unexplored how these students perceive their own experiences in transition to U.S. higher education. Although researchers have studied international students' adjustment and acculturation, international students are usually treated as a homogenous group. It remains relatively unknown how international Chinese doctoral students perceive their own transition experience in the U.S. Therefore, in this study I focused particularly on the important population of Chinese doctoral students and sought to better understand the actual lived experience of these students at a researchintensive institution.

\section{LITERATURE REVIEW}

\section{International Students' Adjustment in Transition}

For any graduate students, regardless of their nationality and native language, transition to graduate school is a challenging process. Tinto (1993), who focused on domestic graduate students, suggested that graduate students experience challenges of both academic and social integration. 
Tinto's findings could be applicable to international Chinese students pursuing doctoral degrees in the U.S. as they need to make adjustments in both academic and social environments. Numerous studies (e.g., Andrade, 2006; Ballard \& Clanchy, 1997; Choi, 2006; Lee \& Carrasquillo, 2006; Lin \& Yi, 1997) have been conducted regarding specific challenges that international students encounter on American campuses. Focusing on international Asian students in the U.S., Hung (2006) found that these students tend to have two essential problems: incompetence in academic English, and unfamiliarity with the new learning environment.

Language barriers were reported to be the most challenging issue, particularly to those non-English native speakers (Mori, 2000; Sato \& Hodge, 2009). Lack of English proficiency could obviously impact students' academic performance. Consequently, academic challenges could make students' transition to a new learning environment more difficult (Lin \& Yi, 1997). In some cases, the language difficulty may decrease international students' confidence in their academic success (Sato \& Hodge, 2009). Researchers (Hayes \& Lin, 1994) also indicated that language barriers could impede international students from engaging in social interactions with American peers and local communities.

In addition to language barriers, international students' experience in U.S. higher education is highly associated with their experience in the U.S. culture (Kim, Yang, Atkinson, Wolfe \& Hong, 2001). International students could experience severe stress at school when adjusting to a different culture (Chen, 2000; Rahman \& Rollock, 2004). They were also found more likely to have psychological or mental issues compared to their American peers (Leong \& Chou, 1996; Mori, 2000). Asian international graduate students, in particular, felt marginalized and had difficulties engaging in social activities with their White peers (Sato \& Hodge, 2009).

Social support was another factor that significantly affects international students' adjustment. Researchers (Hechanova-Alampay, Beehr, Christiansen, \& Van Horn, 2002) pointed out that international students tended to experience less social support than domestic students due to a greater distance from their parents and friends. Focusing on the doctoral experience of Asian international students in science, technology, engineering, and mathematics, Le and Gardner (2010) indicated that support from faculty, advisors, and peer graduate students was an important asset for these students. Perrucci and Hu (1995) found that international graduate students' contact with American students was positively related to their level of satisfaction with academic programs. In contrast, limited social contact in the host country could increase the students' degree of anxiety, depression, and alienation (Chen, 1999). 


\section{International Chinese Students' Transitioning Challenges}

Similar to international students from other nations, Chinese international students face academic and cultural challenges in transition. In fact, these students are one of the international groups that experience greater challenges adapting to the American educational system due to the difference between education in China and the U.S. (Yan \& Berliner, 2009). Numerous researchers (e.g., Jin \& Cortazzi, 2006; Nelson, Badger, \& Wu, 2004; Wilson, 2001) have studied social distance and its impact on Chinese international students' learning experiences in Western cultures. These researchers indicated that challenges faced by Chinese learners could be attributed to the Confucius cultural heritage and the collectivism social context.

Chinese education is viewed as teacher centered, content based, and test driven (Wang \& Kreysa, 2006). Chinese students have been portrayed as diligent learners, but passive, obedient to authority, and having fear of showing different opinions to the instructor (Carson \& Nelson, 1996; Dunbar, 1998; Flowerdew, 1998; Kennedy, 2002; Samuelowicz, 1987). Thus, it is not surprising that Chinese students are not comfortable with U.S. classroom activities, such as participating in group discussions, raising questions in class, and engaging in critical argumentations (Durkin, 2011). In addition to adjusting to a different learning environment, Yeh (2000) pointed out that Chinese international students were more likely to be overlooked on their psychological stress and transitioning challenges in the U.S. because normally they were viewed as students with good work ethics and overachievers.

Although the previous literature studied thoroughly on challenges and difficulties that international students normally encounter in U.S. higher education, most of the literature available is monolithic in nature. In other words, these studies did not distinguish differences between undergraduate, master's, and doctoral experiences nor acknowledge international students are a heterogeneous population. Therefore, I intentionally focused on doctoral students from mainland China and aimed to understand how they perceive their transition from a Chinese education setting into an American one.

\section{Theoretical Framework}

This study employed adult transition theory (Goodman, Schlossberg, \& Anderson, 2006) as its framework and particularly focused on international Chinese doctoral students' transition experiences from an individual perspective. This framework provides a theoretical foundation to understand adult development in transition, as well as coping strategies that can be used to assist individuals experiencing a transition. In addition, this 
theory articulates that each individual may handle transition differently and acknowledges personal differences.

According to Goodman and colleagues (2006), a transition is defined as "any event or nonevent that results in changed relationships, routines, assumptions, and roles” (p. 33). The transition can be classified as anticipated, unanticipated, or nonevents. Chinese doctoral students may experience one or a combination of all three types when transitioning to U.S. higher education. Throughout the transition, individuals may obtain personal growth, but decline is also a possible outcome. Goodman and colleagues identified four major factors that play significant roles in managing adults' transition and may influence their transition outcomes. These factors are situation, self, support, and strategies, also known as $4 S$ factors. Each factor can influence Chinese doctoral students' persistence, retention, and success in pursuing doctoral degrees in the U.S.

\section{METHOD}

In order to explore the essence of shared meaning of the international Chinese graduate students' experiences, I adopted phenomenology as the guiding methodological framework (Moustakas, 1994). Data were primarily collected through focus-group interviews and field notes taken at the interviews.

\section{Research Site and Participants}

All participants were enrolled at a large research-intensive, landgrant University in the Midwestern U.S. In the academic year of 2010-2011, it enrolled over 28,000 students in a wide range of academic majors. Potential respondents were identified through purposeful and referral sampling (Esterberg, 2002). Participants were chosen from students who grew up in mainland China and have not had any experiences in studying overseas prior to pursuing a doctoral degree at the Midwestern University. All of the participants were enrolled in doctoral programs with an F-1 student visa. Recruited by snowballing sampling technique, ten doctoral students from mainland China participated in the study. These participants were from different majors and six of them were female. The average age of the participants was 26.4, with a range of 23 to 32 years of old. They were given pseudonyms of Anling, Bang, Congshan, Diya, Enyang, Feng, Gangdu, Hua, Jiaming, and Kai. Table 1 presents detailed information of these participants. 
Table 1.

Demographic Characteristics of the Participants

\begin{tabular}{llll}
\hline Pseudonyms & Gender & Age & \multicolumn{1}{c}{ Major } \\
\hline Anling & Female & 28 & Business Management \\
Bang & Male & 23 & Computer Science \\
Congshan & Male & 27 & Chemistry \\
Diya & Female & 25 & Communications \\
Enyang & Female & 23 & Biology \\
Feng & Female & 25 & Electronic Engineering \\
Gangdu & Male & 31 & Educational Leadership \\
Hua & Female & 26 & Physics \\
Jiaming & Female & 32 & Curriculum and Instruction \\
Kai & Male & 24 & Agriculture \\
\hline
\end{tabular}

\section{Data Collection}

Data were mainly collected from two focus group interviews in spring 2011, each of which consisted of five participants and lasted approximately 90 minutes. The interview questions were open-ended and semi-structured. These questions were developed based on a pilot interview with two students and revised after expert reviews. The questions centered on the participants' academic, social, and cultural experiences of their arrival in the U.S. I asked participants to discuss difficulties and challenges they have encountered as well as strategies that they applied. I also asked them how their experiences of studying in the U.S. impact their lives and what they have gained from this experience. To provide a natural conventional situation for the participants, interviews were conducted in their native language, Mandarin Chinese. Field notes taken at the interviews were also collected for this study.

\section{Data Analysis}

The interviews were audio recorded and verbatim transcriptions were created for further analysis. The interview records were first transcribed into Chinese and then translated into English. The translation of the transcription was reviewed by two Chinese scholars at the university who have extensive experience translating between Chinese and English. The transcripts were open coded through a first review to identify initial topics or subjects (Esterberg, 2002). Thematic findings were created following additional inductive analyses of categories and coded data. The transcription and its English translation were sent back to each respondent for accuracy checks. Each respondent was invited to add clarification and 
additional information. In so doing, participants had additional opportunity to review, revise, or modify their initial responses. The review resulted in few minor changes and some additional comments regarding their academic and social lives in transition.

\section{Trustworthiness}

Trustworthiness cannot be achieved unless "findings as closely as possible reflect the meanings as described by the participants" (Leitz, Langer, \& Furman, 2006, p. 443). I used several methods to ensure trustworthiness in this study. First, I included doctoral students from a wide variety of majors across the campus to get a fuller understanding of the transition experiences of Chinese students in doctoral programs. Second, I asked the respondents to check the content of the interview transcripts and their translation to enhance the trustworthiness (Lincoln \& Guba, 1985). Additionally, the interviews were conducted in the participants' native language, which allowed them to fully engage in conversations. The translation of the interviews were conducted by experienced translators and reviewed by the participants.

\section{Limitations}

Although this study contributed to the literature in international students' transition, several limitations exist that should be addressed. As with all qualitative research, the findings of the study were not optional for external generalizability. Interpretation of the findings should be carefully used since the emphasis of the study was on reviewing Chinese doctoral students' transition experiences at a U.S. research university. Second, this study conducted focus group interviews without additional follow-up interviews. This may limit the depth of information collected. Third, this study was limited to perspectives of international Chinese doctoral students only. Adding views of American students, faculty, and administrators could lead to more profound findings and more holistic pictures of transition issues of these students.

\section{FINDINGS}

All of the respondents shared their transition experiences and concerns, which were related to mastering a new language, adapting to a new culture, and adjusting to a new academic environment. These respondents also shared their internal changes through interactions with the external environment. Although all respondents were in a relatively early stage of transition, they had seen changes in themselves. The respondents' transition experiences were characterized into three themes: 1) being as an ESL 
learner, 2) tension in relationships, and 3) changes of self-identification.

\section{Being an ESL Learner}

The respondents had heated discussions about their experiences in doctoral programs at the research university. Being an ESL leaner emerged as a prevalent theme in the conversations. These respondents discussed their experiences in classrooms, interactions with faculty and peers, and concerns of being ESL learners on campus.

Silence in the Classroom. Interviews with the participants provided evidence that the Chinese doctoral students were facing difficulties in transitioning to U.S. higher education, particularly to the learning environment in face-to-face classrooms. Diya noted that students in the U.S. are more active in class presentations and discussions while Chinese students tend to remain silent during the activities. She also pointed out that as compared to Chinese faculty, instructors in U.S. play a less dominate role in teaching and learning. As she recommended to other respondents, "Speaking in class is an important way to secure a good score." Jiaming echoed that the more a student speaks in class, the better score for class participation he or she could receive. Although most of the respondents noticed the differences between the two classroom cultures, many viewed the adjustment as a challenging process. Diya did not want to be labeled as a "silent Chinese" but was struggling with changes. She regarded the transition between the two different classroom environments as "a vicious circle.”

Being silent in the classroom was like a vicious circle. I blamed myself every time for not participating in class discussions but the more I blame myself, the more hesitant I become to share my opinions with my classmates.

Being treated as invisible. Admission to highly competitive doctoral programs at the research university demonstrated that the respondents were well prepared for academic study and graduate research. However, this may not guarantee that the students were confident in achieving academic success. Indeed, many were defeated in doctoral studies because they felt that they were being treated as less qualified as compared to American students or regarded as someone invisible. Anling indicated that it was counteractive to her effort of engaging in class discussion when her professor did not seem to care about what she wanted to share. 
I always sit in the first row in the classroom with other three Chinese students so we could be better focused on the lecture.... The professor usually skips our row to only talk to the rest of the class...feels like we were not there. I know that we do not volunteer much to answer his questions...not that we do not want to participate, it just takes us longer time to organize our thoughts in English. We felt being treated as if we were not as intelligent as American peers.

With a similar experience, Enyang reported that an American male student in her study group never responded to her questions in email and even walked away from her when she was explaining her ideas to him.

I explained to him and the other students in my study group what I thought about the project. His response was simply "I don't understand.” So I was explaining again but he just walked away from the discussion.

Lack of Support for ESL Learners. Another challenge of being an ESL learner is lack of support for and understanding of ESL learners in doctoral programs. The respondents reported that although there were resources and support for ESL learners, many of them were at the college level and catered to undergraduate students. Gangdu expressed an urge to improve his English in academic writing, but unfortunately the university writing center was only available for undergraduate students.

The needs of ESL learners were overlooked by instructors in graduate programs. Kai remembered a discouraging conversation with his professor after the first class.

I went to the professor for some clarification about the information that he presented in his lecture. I expressed my concerns of being an ESL learner and indicated that I may need additional help from him. Before I finished my sentence, he responded directly, "Sorry, I cannot help. You need to go back to your ELS teachers.”

Kai repeated several times during the interview that this was the only incident that he had ever encountered in his academic study at the research university. He emphasized that other professors he had met were understandable and supportive. However, he did confess that this conversation discouraged him from pursuing a doctoral degree. 


\section{Tension in Relationships}

The participants consented that transitions had a significant impact on their interpersonal relationships. Coming to the U.S. may cause dramatic changes in their interpersonal relationships: old ones may end and new ones would emerge. The respondents found it challenging to maintain old relationships as well as initiating new friendships when transitioning to a new culture. They also faced challenges of balancing social life and academic study.

Maintaining a Relationship. Distance was reported by the respondents as a significant obstacle in maintaining a relationship although the Internet and other technologies are heavily used to bridge the gap of time differences and geological distance. Several respondents felt that, after they came to the U.S., they grew apart from those whom they have had a close relationship with. Feng sensed detachment from his best friends from middle school soon after he began his journey at the research university.

I never thought that our friendship will be changed because we are at different places, but I started to feel increasing disconnections with my best friends in China.... When I want to call them I have to think twice what time it is in China. I also feel that we do not have much in common to share any more.... I guess it because that we are on different life paths now.

Forming New Friendships. The respondents regarded lack of English proficiency as an obstacle to establish new friendships with students from different linguistic backgrounds. Kai enjoyed meeting new people but reported English as a barrier that keeps him from being fully engaged in opportunities of making new friends.

I was invited by my roommate to hang out with her friends a couple of times, but I felt like an idiot. I only understood parts of their conversations. I felt lost when they were making jokes and became tired of always asking for an explanation.

Hua was excited to meet new people on campus, but soon she found it difficult to really become a member of an existing community. She recognized that getting to know new people was not equivalent to making new friends; friendships do not happen overnight.

I added over 50 "friends" to Facebook during the first few weeks, but I still felt I have nobody to talk with when I am lonely. 
Balance between School Work and Social Life. Most of the respondents reported that there was a tension in balancing school work and social life, especially during their first semester. Congshan experienced struggles with his homework, research responsibilities, and lab experiments. He indicated that he could not afford participating in social activities when trying to survive in such a competitive doctoral program.

Everyone told me that I have to study hard to pass the qualifying examination. I spent almost all of my time in my office, lab, and the library. Plus work, research, and homework, I have to take English classes in order to be qualified as a graduate teaching assistant. I had barely enough time to eat and sleep.

Other respondents expressed similar experiences. Although they would like to spend more time meeting with new friends they set their academic study as the priority when there is a conflict between the two.

\section{Changes of Self-Identification}

Reflecting on their learning and living experiences in the U.S., the respondents confirmed that they were different from their past selves whether they had a rough or smooth transition. The most frequently reported changes include becoming more attentive to cultural diversities, more tolerant with differences, and becoming a more responsible adult.

Cultural Awareness. Most of the respondents indicated that their experiences of studying in the U.S. had fostered a broader cultural awareness and a better preparation for multicultural understandings. Diya referred to understanding a new culture as a different experience of learning a new subject: book knowledge is important but personal experience is essential.

Living in the U.S. provides me with an opportunity to meet people from diverse cultural backgrounds. Book knowledge about cultural differences did not become relevant until I experienced it myself.

Tolerance with Differences. The respondents consented that they became more tolerant with differences as being exposed to cultural diversities in local communities, classrooms, and campus activities. Bang found himself becoming more interested in different views and opinions. In fact, he appreciated every opportunity of communicating with people who had dissimilar perceptions. 
Talking to different people is really fun. It is like a chance to live another life. We should never judge how others should act merely based on our own experiences. Rather, we should have eyes to see the beauty of differences and a heart to appreciate them.

Becoming a Responsible Adult. Being far away from home and family, the respondents agreed that the U.S. experiences helped them become more mature individuals and more responsible adults. Enyang never needed to take care of things such as cooking, grocery shopping, or doing laundry when she was living with her parents in China. She struggled to manage her own life when she first came to study in the U.S. At the time of being interviewed, Enyang was glad to share with the group how much she had achieved in the past year.

I never considered how much time you could spend on cooking when you don't know how [laugh]. I am now very proud of myself that I am becoming a good cook.... I enjoyed the feeling that I can take good care of myself and feel more grown-up.

\section{DISCUSSION}

Through group sharing and discussions, this study revealed challenges that international Chinese students experienced in doctoral programs at a research-intensive university. The findings of the study indicate that issues of the Chinese doctoral students in transition are more likely to be neglected compared to undergraduate students because they are normally viewed as more mature, better prepared for academic studies, and less financially challenged - all of them received stipends from the institution by serving as a teaching or research graduate assistant. According to Goodman and colleagues (2005), the students' transition experiences are discussed from four perspectives: situation, self, support, and strategies.

\section{Situation}

Respondents reported coming to study in the U.S. as a positive situation although they encountered expected and/or unexpected difficulties. These students' decision to study in the U.S. was anticipated and all considered being admitted to a U.S. doctoral program as a significant accomplishment in their life. It is deeply rooted in Chinese traditional culture that academic achievement is an honor to the self and the family (Yan \& Berliner, 2009). All of the participants had a thorough academic preparation prior to their application. That is, all of the respondents 
performed well on the Graduate Record Examinations (GRE) and English proficiency tests: Test of English as a Foreign Language (TOEFL) or International English Language Testing System (IELTS). This echoed with other research (Le \& Gardner, 2010; Sato \& Hodge, 2009) that international Asian graduate students are hard-working, self-efficient, and highly motivated to accomplish academic success.

However, the unanticipated challenges, such as unsupportive conversations with professors and peers, challenges in establishing new relationships, and difficulties of balancing study, work, and social life, led the respondents to feel defeated and unconfident in their transition. This implies that the Chinese doctoral students may be well prepared for their academic studies, but might overlook non-academic challenges. This may suggest that future doctoral degree seekers from mainland China should consider studying in the U.S. as a more holistic experience rather than academic-related only.

\section{Self}

Through the transition, respondents reported positive changes of the self. Becoming more mature, more responsible, and more independent were highlighted by the respondents. These students reported that the transition from one culture to another increased their tolerance with differences and enhanced their awareness of cultural diversities. Many expressed their appreciation of the first-hand experiences in multi-cultural understanding. Sato and Hodge (2009) have provided similar evidence that studying overseas can broaden international students' cultural understanding and promote their self-awareness.

Conversations with the respondents revealed certain cautiousness as being afraid of making mistakes or being embarrassed. This finding confirmed early research (Carson \& Nelson, 1996; Dunbar, 1998; Flowerdew, 1998; Kennedy, 2002; Samuelowicz, 1987) on characteristics of Chinese learners and impact of Confucius-heritage culture on Chinese students' learning. Bond (1992) pointed out that the concept of "face" greatly impacts Chinese students' learning. Since "having face” means that one has status in front of others, it is not surprising that Chinese students fear "loosing face" by making any mistakes in class. Being silent in the classroom and having troubles in making new friends were not merely results of low English proficiency but also a high risk avoidance characteristic of Chinese students. This characteristic could imply challenges in transition if the students are still struggling with the use of English. 


\section{Support}

Leaving the home country and departing from their support system in mainland China, the respondents described their transition to the U.S. as a challenging process. They reported that maintaining old relationships in China and initiating new friendships with American students were particularly difficult. The respondents noted that they usually turned to old friends in China or other Chinese students on campus for help and support. All respondents expressed willingness to make new friends with American students or other international students, but indicated that it was more difficult due to language barriers and cultural differences.

None of the respondents mentioned using institutional services such as International Students and Scholars Office or Consulting Center as useful sources for information and problem solving. On the contrary, the students expressed concerns about lack support for international graduate students, particularly doctoral students. This may imply that the services provided at the university level are not catered to the needs of doctoral students. This may also indicate that the Chinese students are not fully aware of the available support mechanisms on campus or they feel intimidated to ask for help. Early research (Heggins \& Jackson, 2003; Zander, 1983) pointed out that Asian international students had a tendency to keep problems and challenges to themselves and may view seeking help as a sign of weakness. Support directly from instructors was considered important to the respondents' success in their academic endeavor. Respondents indicated that they valued a professor's encouragement and appreciated their understanding of ESL learners' experiences. They hoped that the faculty could recognize the challenges faced by international students, but sought to be treated equally with American and other English speaking students. Hodgson and Simoni (1995) found that students who do not perceive the institution as being supportive do not function well academically or psychologically. This may indicate that the lack of support from faculty in doctoral programs could greatly hinder the international Chinese students' academic performance.

\section{Strategies}

Many strategies that the respondents used in transition have been discussed above. These students sought support and help from long-lasting relationships in China or other Chinese students on campus. Spending additional time and effort on coursework was an important strategy that the respondents adopted to cope with academic challenges. These participants were willing to dedicate themselves to study and research to ensure their academic success. Improving English skills was also reported as a way to overcome challenges in academic study as well as interacting with 
American peers. Thus, the international Chinese doctoral students should be encouraged to become more attentive to cultural challenges and be better prepared for socio-cultural transition. This will help these Chinese learners alleviate their stress on cultural adjustment and ultimately benefit their academic endeavor.

\section{IMPLICATIONS AND CONCLUSION}

This qualitative study purposefully explored transition experiences of international Chinese students in doctoral programs at a Midwestern research university. Through the three emerging themes, being an ESL learner, tension in relationships, and changes of self-identification, the findings of the study offer a better understanding of international Chinese students pursuing doctoral degrees as a unique group of learners. This study discussed these students' transition experiences as well as four major factors that have significant influence on their transition outcomes: situation, self, support, and strategies. This study encourages faculty, administrators, and education practitioners to acknowledge, respect, and embrace an increasingly diverse world of doctoral students.

There are many strategies that U.S. colleges and universities can employ to support international Chinese doctoral students and possibly other international student groups. First, instructors of doctoral courses and advisors who work with international Chinese students might be encouraged to develop better understandings of Chinese students' special challenges and needs so that they can be more aware of their difficulties in transition (Yan \& Berliner, 2009). Specifically, differences in learning styles between Chinese learners and their American peers should be made known to the instructors and advisors and necessary pedagogical reforms are encouraged to be carried out (Huang, 2012). Second, as supported by previous research (Heggins \& Jackson, 2003; Jacob \& Greggo, 2001; Ku, Lahman, Yeh, \& Cheng, 2008; Rose, 2005), mentoring programs could be established to enhance international students' transition experiences. Both faculty-student and peer mentoring programs benefit international doctoral students who are struggling with adjustment issues.

U.S. higher education institutions can assist international doctoral students to establish a support network and provide them with more opportunities (both academic- and non-academic related) to be mingled with people from other cultures. It was found that a support network is a critical factor in the successful adjustment of international students (Carr, Koyama, \& Thiagarajan, 2003). Lastly, U.S. colleges and universities could turn their focus from what international Chinese students need to what they can contribute. Thus, these doctoral students would be provided opportunities to 
share their own experiences and knowledge. This strategy can create a more supportive environment for both international and domestic students, who possess different backgrounds and knowledge, to capitalize on each other's strengths (Huang, 2012).

Since an increasing number of students from China will continue to study in U.S. higher education at a doctoral level, their transition experiences deserve additional and sustained attention. Future studies may consider individual differences in their transition. Within the group of international Chinese doctoral students, demographic characteristics, personal goals, and prior academic background may lead to different emphasis on their transitional experiences in the U.S. These individual differences need to be recognized and further studied. Future researchers can identify both short-term and long-term aspects of transition. Focusing on the transitional process, future study can identify changes overtime. This design will allow U.S. higher education institutions to better understand these students' experiences at different stages of transition, thus developing better strategies to support these students. Future study can take nationality into consideration. International students from different regions of the world may have very different experiences in transition. Students from English speaking countries, for instance, would probably not regard language as a critical barrier as students whose native language is not English. Through an increased understanding of this particular group of international students, U.S. higher education institutions can work toward ensuring a more satisfactory transition experience and higher completion rates for international Chinese doctoral students and potentially for all other international students.

\section{REFERENCES}

Andrade, M. S. (2006). International students in English-speaking universities: Adjustment factors. Journal of Research in International Education, 5(2), 131-154.

Ballard, B., \& Clanchy, J. (1997). Teaching international students: a brief guide for lecturers and supervisors. Canberra: IDP Education Australia.

Bond, M. (1992). Beyond the Chinese face: Insights from psychology. Hong Kong: Oxford University Press.

Brainard, J. (2005, May 20). Foreign scientists' recruitment urged. Chronicle of Higher Education, pp. A22.

Carr, J. L., Koyama, M., \& Thiagarajan, M. (2003). A women's support group for Asian international students. Journal of American College Health, 52, 131-137. 
Carson, J. G., \& Nelson, G. L. (1994). Writing groups: Cross-cultural issues. Journal of Second Language Writing, 3, 17-30.

Chen, C. P. (1999). Common stressors among international college students: Research and counseling implications. Journal of College Counseling, 2, 49-65.

Choi, T. (2006). Asian international students' academic adjustment in a U.S. graduate school and Stanton-Salazar's framework. Pacific Asian Education, 18, 51-68.

Dalton, J. C. (1999). The significance of international issues and responsibilities in the contemporary work of student affairs. New Directions for Student Services, 86, 3-11.

Dunbar, R. J. M. (1998). The social brain hypothesis. Evolutionary Anthropology, 6, 178-190.

Durkin, K. (2011). Adapting to western norms of critical argumentation and debate. In L. Jin \& M. Cortazzi (eds.), Researching Chinese Learners (pp. 274-291). New York, NY: Palgrave Macmillan.

Feller, B. (2005, July 26). Business groups unite to command more attention for math, science. Associated Press Newswires. Retrieved from http://www.

rutlandherald.com/apps/pbcs.dll/article?AID=/20050727/NEWS/50 $726007 / 1011$

Flowerdew, L. (1998). A cultural perspective on group work. ELT Journal, 52 (4), 323-328.

Esterberg, K. G. (2002). Qualitative methods in social research. Boston: McGraw-Hill.

Goodman, J., Schlossberg, N. K., \& Anderson, M. (2006). Counseling adults in transition: Linking practice with theory. New York, NY: Springer.

Hechanova-Alampay, R., Beehr, T.A., Christiansen, N.D. And Van Horn, R.K. (2002). Adjustment and strain among domestic and international student sojourners: A longitudinal study'. School Psychology International, 23(4), 458-74.

Hayes, R. L., \& Lin, H. (1994). Coming to America: Developing social support systems for international students. Journal of Multicultural Counseling \& Development, 22(1), 7-16.

Heggins, W. J., \& Jackson, J. F. L. (2003). Understanding the collegiate experience for Asianinternational students at a Midwestern research university. College Student Journal, 37(3), 379 -391.

Heyward, M. (2002). From international to intercultural: Redefining the international school for a globalized world. Journal of Research in International Education, 1(1), 9-32.

Hodgson, C. S., \& Simoni, J. M. (1995). Graduate student academic and 
psychological functioning. Journal of College Student Development, 36, 244-253.

Huang, Y. (2012). Transitioning challenges faced by Chinese graduate students. Adult Learning, 23(3), 138-147.

Hung, H. (2006). What is missing in U.S. higher education: Looking into the learning experiences of Asian international students from cognitive and sociocultural perspectives. Journal of Curriculum and Pedagogy, 3(2), 168-192.

Institute of International Education. (2013a). International student totals by place of origin, 2011/12 - 2012/13. Open Doors Report on International Educational Exchange. Retrieved from http://www.iie.org/opendoors

Institute of International Education. (2013b). International students by academic level and place of origin, 2012/13. Open Doors Report on International Educational Exchange. Retrieved from http://www.iie.org/opendoors

Jacob, E. J., \& Greggo, J. W. (2001). Using counselor training and collaborative programming strategies in working with international students. Journal of Multicultural Counseling and Development, 29, 73-88.

Jin, L., \& Cortazzi, M. (2006). Changing practices in Chinese cultures of learning, Language, Culture and Curriculum, 19(1), 5-20.

Kennedy, P. (2002). Learning cultures and learning styles: Mythunderstandings about adult (Hong Kong) Chinese learners. International Journal of Lifelong Education, 21(5), 430-445.

Kim, B. S. K., Yang, P. H., Atkinson, D. R., Wolfe, M. M., \& Hong, S. (2001). Cultural value similarities and differences among Asian American ethnic groups. Cultural Diversity \& Ethnic Minority Psychology, 7, 343-361.

Ku, H.-Y., Lahman, M. K. E., Yeh, H.-T., \& Cheng, Y.-C. (2008). Into the academy: preparing and mentoring international doctoral students. Educational Technology Research and Development, 56, 365-377.

Le, T. \& Gardner, S. K. (2010). Understanding the doctoral experience of Asian international students in the science, technology, engineering, and mathematics (STEM) fields: An exploration of one institutional context. Journal of College Student Development, 51(3), 252-264

Lee, K., \& Carrasquillo, A. (2006). Korean college students in the United States: Perceptoins of professors and students. College Student Journal, 40, 442-456.

Leitz, C., Langer, C., \& Furman, R. (2006). Establishing trustworthiness in social work. Qualitative Social Work, 5, 441-458.

Leong, F. T. L., \& Chou, E. L. (1996). Counseling international students. In 
P. B. Pedersen, J. G. Draguns,W. J. Lonner, \& J. E. Trimble (Eds.), Counseling across cultures (4th ed., pp. 210-242). Thousand Oaks, CA: Sage.

Lin, J. C. G., \& Yi, J. K. (1997). Asian international students' adjustment: Issues and program suggestions. College Student Journal, 31(4), 473-479.

Lincoln, Y., \& Guba, E. (1985). Naturalistic inquiry. Beverly Hills, Sage.

Mori, S. (2000). Addressing the mental health concerns of international students. Journal of Counseling and Development, 78(2), 137-144.

Moustakas, C. (1994). Phenomenological research methods. Thousand Oaks, CA: Sage.

NAFSA (2012). The economic benefits of international students to the U.S. economy: Academic year 2011-2012. Retrieved from http://www.iie.org/Research-and- Publications/OpenDoors/Data/Special-Reports/Economic-Impact-of-InternationalStudents

National Science Foundation (NSF), National Center for Science and Engineering Statistics. 2012. Doctorate Recipients from U.S. Universities: 2011. Special Report NSF 13-301. Arlington, VA. Retrieved from http://www.nsf.gov/statistics/sed/.

Nelson, L.J., Badger, S., \& Wu, B. (2004). The influence of culture in emerging adulthood: Perspectives of Chinese college students. International Journal of Behavioral Development, 28, 26-36.

Perrucci, R., \& Hu, H. (1995). Satisfaction with social and educational experiences among international graduate students. Research in Higher Education, 36(4), 491-508.

Peterson, D. M., Briggs, P., Dreasher, L., Horner, D.D., \& Nelson, T. (1999). Contributions of international students and programs to campus diversity. New Directions for Student Services, 86, 67-77.

Rahman, O., \& Rollock, D. (2004). Acculturation, competence, and mental health among South Asian students in the United States. Journal of Multicultural Counseling and Development, 32, 130-141.

Rose, G. L. (2005). Group differences in graduate students' concepts of the ideal mentor. Research in Higher Education, 46, 53-80.

Samuelowicz, K. (1987). Learning problems of overseas students. Higher Education Research and Development, 6, 21-134.

Sato, T., \& Hodge, S. R. (2009). Asian international doctoral students' experiences at two American universities: Assimilation, accommodation, and resistance. Journal of Diversity in Higher Education, 2(3), 136-148.

Tinto, V. (1993). Leaving college: Rethinking the causes and cures of student attrition ( $2^{\text {nd }}$ ed.). Chicago, IL: University of Chicago Press. 
Wang, V. C. X., \& Kreysa, P. (2006). Instructional strategies of distance education instructor in China. The Journal of Educators Online, 3(1), 1-25. Retrieved from http://www.thejeo.com/Archives/Volume3Number1/WangFinal.pdf

Wilson, M. S. (2001). Cultural considerations in online instruction and learning. Distance Education, 22(1), 52-64.

Yan, K., \& Berliner, D. (2009). Chinese international students' academic stressors in the United States. College Student Journal, 43(3), 939960.

Yeh, Y. (2000). Chinese student stress: A further clarification of Merton's anomie theory. Unpublished doctoral dissertation, University of Pennsylvania.

Zander, A. (1983). The value of belonging to a group in Japan. Small Group Behavior, 14, 3-14.

YI (LEAF) ZHANG is an Assistant Professor of Educational Leadership \& Policy Studies in the College of Education \& Health Professions at the University of Texas at Arlington. Correspondence concerning this article should be addressed to Yi (Leaf) Zhang, Box 19575, 701 Planetarium Place, 103D Trimble Hall, University of Texas at Arlington, Arlington, Texas 76019-0575. E-mail: Lyzhang@uta.edu 